\title{
Sobre o Manifesto Regionalista
}

\author{
concernig to Regionalist manifesto \\ Relativo al manifiesto regionalista
}

Joaquim Falcão ${ }^{1}$

\section{Resumo}

FALCÃO, Joaquim. Sobre o Manifesto Regionalista. Rev. C\&Trópico, v. 45, n. 1, p. 43-52, 2021. DOI: https://doi.org/10.33148/cetropicov45n1(2021)art3

O presente ensaio reflete sobre a contemporaneidade brasileira à luz do legado de Gilberto Freyre deixado por seu Manifesto Regionalista. Argumenta-se que a obra de Freyre antecipou diversos fenômenos na vida brasileira como a inclinação ao globalismo, o equilíbrio dos contrários e diversos aspectos da vida privada, além de elementos como o urbanismo, a arquitetura e a culinária. Acerca deste último aspecto, debruça-se sobre o impacto de dois pratos eminentemente brasileiros, vindos de Pernambuco: o escondidinho e o arrumadinho.

Palavras-chave: Manifesto regionalista. Globalismo. Urbanismo. Culinária. Vida privada.

\section{Abstract}

FALCÃO, Joaquim. concernig to Regionalist manifesto. Rev. C\&Trópico, v. 45, n. 1, p. 4352, 2021. DOI: https://doi.org/10.33148/cetropicov45n1(2021)art3

This essay exams the Brazilian contemporaneity through the legacy left by Gilberto Freyre in his Manifesto Regionalista [The Regionalist Manifesto]. Freyre's work anticipated several phenomena in Brazilian society, such as the inclination towards globalismo, the balance of the opposites and aspects of the private life. Also, elements of urbanism, architecture and gastronomy are observable through the lens of the Regionalist Manifesto. About this last aspect, this work exams the impact of two dishes eminently Brazilian, which came from Pernambuco: the escondidinho and the arrumadinho.

Keywords: Regionalist manifesto. Globalism. Urbanism. Gastronomy. Private life.

1 Doutor em Educação péla Universidade de Genebra; Membro da Academia Brasileira de Letras, Conselheiro da Transparência Internacional e Professor de Direito Constitucional. E-mail: joaquim.falcao@ academia.org.br Orcid: https://orcid.org/0000-0001-8926-4595. Este texto é uma expansão a partir de FALCÃO, Joaquim. Não é só arroz doce: regionalismos e globalização. In: FREYRE, Gilberto. Manifesto Regionalista. Recife: Fundaj, 2016, 7-22. 


\section{Resumen}

FALCÃO, Joaquim. Relativo al manifiesto regionalista. Rev. C\&Trópico, v. 45, n. 1, p. 4352, 2021. DOI: https://doi.org/10.33148/cetropicov45n1(2021)art3

Esto ensayo reflete acerca de la contemporaneidad brasileña a la luz del legado de Gilberto Freyre en su Manifesto Regionalista. El trabajo de Freyre anticipó diversos fenómenos en la sociedad brasileña, por ejemplo la inclinación al globalismo, el equilibrio de contrarios y aspectos de la vida privada. También ha predijo acerca de elementos de urbanismo, arquitectura y culinaria. Respeto a este ultimo aspecto, este trabajo se centra en dos platos eminentemente brasileños, que vieron de Pernambuco: el escondidinho y el arrumadinho.

Palabras clave: Manifesto Regionalista. Globalismo. Urbanismo. Culinária. vida privada.

\section{Introdução}

Gilberto Freyre sempre disputou com os professores sociólogos da USP o trono de Imperador das Ideias (FALCÃO, 2010). Quem seria o melhor e verdadeiro intérprete do Brasil? Não me espantaria se essa disputa, ao mesmo tempo de fundo psicológico na área das ciências sociais, tivesse sido grande estímulo ao Manifesto Regionalista.

Do ponto de vista cultural e geográfico, pode-se falar de uma região Norte ou de uma região Nordeste. Aí existem suficientes homogeneidades integradoras. Sobretudo ambiental. Talvez até exista uma região Sul, devido à hegemonia da colonização germânica.

Mas dificilmente se pode afirmar que exista cultural e sociologicamente uma região Sudeste, unindo, como iguais, São Paulo, Minas Gerais, Rio de Janeiro e Espírito Santo. Pode-se até falar, como alguns historiadores falaram, de pactos políticos temporários, com base em economias complementares, como a república do café com leite. Mas entre estes estados, são muitas as diferenças culturais, raciais, geográficas, e mesmo econômicas.

Ao contrário, diz o Manifesto, "somos um conjunto de regiões antes de sermos uma coleção arbitrária de 'Estados', uns grandes, outros pequenos, a se guerrearem economicamente".

Ao levantar o tema dos regionalismos, Gilberto teria tentado ocupar uma casa no jogo de xadrez das ideias, que São Paulo dificilmente poderia. Antirregionalismo tem sido, muitas vezes, a marca de São Paulo.

São Paulo não é regional. Nem se acredita regional. A grande São Paulo se acredita, sobretudo, cosmopolita. São Paulo não faria a defesa dos regionalismos. Nunca fez. São Paulo sempre foi ator principal na guerra econômica entre estados. Na guerra fiscal, diríamos hoje. O ego paulista, muitas vezes, é maior que regionalismos.

Raymundo Faoro (2004) dizia que existe um "mistério cultural nordestino, para quem vê do sul para o norte (...) O mistério está além da geografia e das particularidades regionais". 


\section{O Manifesto tenta desvendar e explicar este mistério}

Freyre coloca o regionalismo como uma barreira à imitação "cega e desbragada" da novidade estrangeira que São Paulo e Rio de Janeiro praticavam. O culto aos estrangeirismos. Francesismos. Uma barreira, diria Sergio Tavolaro (2013), a favor da descentralização da influência europeia por aqui, nos trópicos.

Entretanto, como hoje não é ontem, para compreender o Manifesto Regionalista, é melhor irmos além desta disputa. Às vezes explicita, às vezes não, sempre latente.

O que nos interessa é o grau de perenidade do Manifesto, 95 anos depois. O que teria a dizer, por exemplo, sobre a globalização de hoje? Pós-Trump, pós-Brexit, pós-pandemia?

Gilberto não era somente produtor, difusor e sedutor de ideias. Foi principalmente estrategista do pensamento. A sua flexibilidade, contradições autodeclaradas e antecipadas deixavam o interlocutor, muitas vezes, perplexo. O que, a si, proporcionava sabor imenso.

"Sou inacadêmico." "Sou e não sou sociólogo." "Não explico, apenas compreendo." "Sou regional, mas não antinacional." "Meu método de pesquisa são todos, e nenhum”. E por aí vamos. Foi sempre alvo móvel. O interlocutor sem poder capturá-lo.

Sua capacidade de ver as contradições, teses e antíteses sociologicamente - o senhor e escravo, e, politicamente, o nacional, o regional e o estadual, por exemplo, sem necessariamente chegar a sínteses fechadas - incomodava a muitos.

Vivíamos época em que interpretar o Brasil era, sobretudo, fazer sua síntese. Mas fazer sínteses, para Gilberto, seria como parar o tempo, fechar a história, descartar a possibilidade.

Sua flexibilidade analítica e metodológica tinha muito de convicção. Mas tinha também muito de estratégia intelectual competitiva.

Na tentativa de reduzir as contradições de que tanto gostava, alguns de seus competidores tentaram vincular sua obra a um só destino: a defesa do equilíbrio das contradições sociais. Ao equilíbrio das trocas, e até dos afetos, desiguais. Gilberto seria o porta-voz, o intérprete conservador do aparente equilíbrio social.

A contradição inclusive de classes sociais não tenderia ao equilíbrio ou composição, mas à explosão, à revolução burguesa, como anunciava Florestan Fernandes.

Melhor teria sido vincular sua interpretação do Brasil como a busca do instável equilíbrio dos contrários. Ou do mutável equilíbrio dos contrários. Ou do equilíbrio desequilibrável dos contrários.

Compreender o Brasil, a partir do Brasil, com precisão empírica, fatos somando aos fatos, através da sociologia do cotidiano, com equilíbrios e desequilíbrios, e apenas sugerir e insinuar movimentos e processos mais amplos, quase sempre inconclusos, mas que poderiam ter sido conclusos, não foi erro metodológico. Foi matriz estratégica.

A tão louvada plasticidade da obra de Gilberto não dizia respeito apenas às formas literárias com que revestiu formas sociais. Diz respeito também ao movimento temporal de sua interpretação do Brasil, de teses sem antíteses. De antíteses sem sínteses. De equilíbrios repletos de desequilíbrios. Tudo aberto ao possível. No caso, ao futuro. 
Daí a pertinência da pergunta há pouco feita. O Manifesto Regionalista esteve, está ainda, aberto ao mundo pós-global que parece se avizinhar? Qual sua permanência ou impermanência?

"Claro que sim. O Manifesto é uma antecipação da globalização. Mas com muitas limitações e imperfeições”, Gilberto poderia ter, imaginariamente, respondido com brilho nos olhos. Com sorriso malandro, a antecipar xeque mate.

Encontramos no Manifesto clara oposição a um globalismo desvairado e a algumas antecipações.

Sua estratégia intelectual era descritiva e interpretativa. Mas prescritiva quanto à visão de futuro para o Brasil, lugar ao mundo, na civilização híbrida, tropical, miscigenada. Lugar próprio.

O caráter antecipatório de seus estudos socioantropológicos e históricos se dava através da ênfase de algumas variáveis já observáveis, mas até então escondidas. Despercebidas.

O Manifesto é uma antecipação de pautas nunca dantes nos trópicos valorizadas.

\section{O manifesto}

Quais são estas antecipações? Antes, importa sublinhar o método a partir do qual o Manifesto foi elaborado. O método é começo de tudo. Foi antecipação também. Alguns até o consideram antecipação mundial, global mesmo, nas ciências sociais e históricas.

O Manifesto é: "Dize-me de teu método e dir-te-ei quem és".

Sua estratégia não foi deduzir o Brasil a partir da dogmatização que ele identificava no culto dos estrangeirismos. Do padrão civilizatório europeu depois americanizado. Não foi a universalização da Europa. Nem mesmo sua tropicalização.

Seu método lhe permitiu escapar da interpretação do Brasil a partir de sua organização política e pública em voga, como Evaldo Cabral de Mello (2001) certeiramente apontou. Gilberto inovou através da história social da vida privada. Do cotidiano do brasileiro. No caso, do alagoano, baiano, pernambucano, sergipano. Do nordestino. Do regional.

A compreensão da vida privada deveria ser o ponto de partida, a matriz da organização nacional. E não vice-versa. A força de seus argumentos vem da descoberta e da valorização deste cotidiano, aqui gerado. E não, ailleurs. Ou melhor, acolá. Inverte o jogo.

Por isto, o Manifesto não é um documento sobre importação dos vanguardismos europeus. É um documento de exportação de tradições e invenções tropicais observáveis. É como se Gilberto quisesse desenhar um autônomo "Brazilian way of life". Ambição demais!

Demais?

A atual globalização, cada vez mais contestada pelas competições nacionalistas, foi moldada pela hegemonia do "American way of life" a partir da Segunda Grande Guerra. Inicialmente, expande-se pragmaticamente como organização integradora dos mercados. Através do controle da informação, tecnologia e finanças. 
O Manifesto vai do máximo ao mínimo. "Nosso movimento não pretende senão inspirar uma nova organização do Brasil." Até uma sugestão mínima: "Que alguém tome a iniciativa de estabelecer, no Recife, um café ou restaurante em que não falte a cor local - umas palmeiras, umas gaiolas de papagaios, um caritó de guaiamum”.

O que se diga logo, pode até ter soado exótico para a época: um caritó de guaiamum na entrada do restaurante! Mas não seria para os dias de hoje. Pois os franceses assim fazem com suas atraentes bancadas de ostras na entrada de suas brasseries. Os italianos com suas vitrines de peixes frescos na entrada de seus restaurantes de comida mediterrânea. Os japoneses com seus balcões de sushi. Os portugueses com suas pastelarias. O Brasil com seus botequins de pés encharcados no chão batido da realidade nossa.

A descoberta do quotidiano é mais do que apenas novo método de se compreender a história social. Tem sido o poderoso instrumento a partir do qual se organiza a economia e a cultura global. É o começo, o fim e o meio, diriam Paulo Coelho e Raul Seixas, de um sistema, inclusive industrial, de produção global.

Não é apenas a busca de uma etérea "identidade nacional", como muitos leram na obra de Gilberto. Não é só arroz doce.

É estímulo concreto a determinado tipo de consumo que desencadeia o desenvolvimento econômico dos países na dianteira de sua produção. Move hearts and minds. Não por menos, a China e os países asiáticos se inserem na globalização protegendo mais e mais seus "Asian ways of life".

Só se engana quem quer. Estamos assistindo vertiginosa universalização da estética chinesa, no vestir, na arquitetura, no design, nos sentimentos e valores sociais, na culinária, no corpo apolíneo, não mais dionisíaco do $M c D o n a l d ' s$, e por aí vamos. Em vez de tapetes, tatames.

A opção de Gilberto pela história social da sua vida privada e sua tentativa de generalizá-la para o Brasil foi o método necessário para produzir sua obra. Mas não foi a condição suficiente.

A condição suficiente foi que a própria história social da vida privada brasileira começasse pela vida pessoal. Do próprio Gilberto. Foi história social através de sua própria vida privada. Gilberto foi o sociólogo ou o antropólogo de si mesmo e com ambições e manias de grandeza. De muita grandeza. E isto lhe antecipou insights e lhe levou à fama. E à guerra.

O patriarcalismo estava nele próprio. No anel de pesado ouro e brasões, usada com orgulho. Anel de coronel, como se chamava, ou heráldico? Ou os dois? Gilberto não fez a sociologia da vida cotidiana dos outros, como fazem em nome da objetividade, da indispensável separação entre sujeito e obra, a maioria de cientistas sociais que se pretendem exatos. Gilberto assumiu fazer a sociologia da vida cotidiana de si mesmo. E muda tudo. Saiu do armário onde o sujeito pretendia se esconder e desaparecer dentro do objeto. Ilusão à toa, hoje sabemos.

Foi nesta condição, ser seu auto intérprete, ato e fato, aliada ao famoso e nunca escondido egocentrismo, que moldou o intelectual e sua obra. Foi um ególatra confesso e satisfeito. Valorizava mais receber em Apipucos do que ser recebido no Catete ou no Planalto. Nas ciências sociais, fez sua própria psicanálise. 
No programa de televisão de Barbosa Lima, dizia que suas relações com Deus eram boas e com Deus conversava de igual para igual. Para o repórter Geneton Moraes Neto, declarava-se o único e mais importante brasileiro vivo. Sendo os mortos, competidores, apenas Villa-Lobos e Santos-Dumont.

Muitos viram essa egolatria como patética, folclore ou desvio de personalidade. Pode até ter sido também. Mas, antes de tudo, foi um impulso decisivo para a criação de um novo método: o da história social da vida privada pessoal. Onde o sujeito, o autor, se dilui no objeto e na obra. E assim pode identificar o patriarcalismo e o patrimonialismo, que, em diferentes versões, estava presente em sua e na nossa história também. Como bem ou como mal. Sob diversas alcunhas. Até hoje.

Gilberto teve vida pública. Foi deputado e constituinte. Foi criador, gestor de instituto governamental de pesquisa. E mais tarde militante político. Mas não transformou nenhuma destas atividades de seu cotidiano em objeto de suas pesquisas. Como o fez com sua casa.

O objeto sempre foi sua vida privada, a casa, as relações de parentesco, a comida, as relações de dominação sociais, econômicas, a sexualidade, o afeto, o vestir, a religiosidade, as raças e por aí fomos. O desejo. O que Mangabeira Unger chamaria de sentimentalismo das trocas desiguais.

Seu autocentrismo vai lhe dar insights e descobrir ou antecipar hábitos que lhe fizeram peculiar. Lembro-me de conversa com o "metteur en scene" dos filmes de Luchino Visconti. Dizia que o segredo de Visconti ter sido o grande intérprete e ao mesmo tempo o grande crítico da burguesia italiana do século passado, através, por exemplo, do clássico "O Leopardo", tinha sido o fato de o próprio Visconti ter pertencido a essa burguesia. Conhecia como o tecer de dentro se prolongava no tecer para fora.

Como o chileno Humberto Maturana acreditava, o observador é aquele que é, e o que é, está em seus olhos.

Paulo Augusto Franco diz que Gilberto começava a fazer sociologia sobre o "outro", e terminava por falar de si mesmo. Ou terá sido o contrário?

Não é por menos que uma principal antecipação do Manifesto em relação à globalização é justamente a questão do urbanismo. Da diferenciação entre as cidades e da sua adequação ao meio geofísico. É a ecologia urbana. Tão em voga e urgente agora na discussão sobre as "smart cities".

Sua memória pessoal era plena de casas-grandes e senzalas e, na cidade, de sobrados e mocambos. Saindo de sua vida privada, não ia para a organização política pública ou econômico-empresarial. Abrindo o portão, ia para a rua do social, como vai sublinhar mais tarde Roberto DaMatta. Encontrava a sociedade e não o governo.

Seu primeiro texto para o Iphan é sobre a defesa dos mocambos como exemplo de ecologia urbana.

O Manifesto investe com força contra os engenheiros simplistas, místicos do cimento armado e mistagogos. Contra as avenidas largas e a gente que há anos nos domina, que só sabe derrubar igrejas. Defende as ruas estreitas, mais afeitas às sombras, mais protetoras do homem do que "o vidro nos países de pouca luz e de sol parecido com a lua". 
O Manifesto é contra "gente que não gosta de árvores".

Estaria Gilberto, neste caso, criticando Oscar Niemeyer ou mesmo Lúcio Costa? Provavelmente não. O manifesto é de 1926, e o Iphan só veio a ser criado em 1937. Mas, claramente, já antecipa os caminhos divergentes que vieram a trilhar.

Lúcio Costa comandou com mão de ferro, autoritária mesmo, o Iphan. Transformou-o numa organização de ideologia arquitetônica única. A do sincretismo, ou mélange, entre o barroco luso-mineiro e o modernismo franco-carioca. Ambos de casas-grandes. Sem mocambos.

Em nome deste monopólio ideológico, permitiu a construção de uma curvilínea passarela de pedestres, por debaixo de um agressivo viaduto na Praça XV, no Rio de Janeiro. Ambos faziam um crucifixo que se ajoelhava aos pés da entrada principal do Paço Imperial.

Já o Manifesto defendia uma ecologia urbana mais protetora dos habitantes sob o implacável sol dos trópicos. Foi contrário aos modernistas quando defendiam que as cidades deviam ser todas "abertas ao sol e aos olhos dos turistas".

Quem hoje pode pensar em uma cidade sustentável sem pensar em sua ecologia urbana? Nesta trilha, Gilberto, mais tarde, avançaria e, com Jayme Lerner, iria defender o "rurbano", a integração campo-cidade.

Outra antecipação de pauta global é, sem dúvidas, a gastronomia. Ou, simplesmente, a comida. A tal ponto que diz: “...uma cozinha em crise significa uma civilização inteira em perigo: o perigo de descaracterizar-se”.

Hoje constata-se a feroz competição global entre o hot dog, a pizza, o sushi, o taco, a pâtisserie, a esfirra, o miojo e por aí vamos.

"Não só com os problemas de belas artes, de urbanismo, de arquitetura, de higiene, de engenharia, de administração deve-se preocupar o regionalista: também com os problemas de culinária, de alimentação, de nutrição."

\section{O ESCONDIDINHO E O ARRUMADINHO}

Para Gilberto Freyre, a culinária é uma das permanências de nossa identidade. Não seria modernismo alienígena. Sobretudo a culinária, da nossa maioria, que emerge dos pés nus do chão batido, de nossa pobreza. Criada, expandida e saboreada aqui no Brasil. Não copiava a arte e literatura europeias. Como a Semana de 22, já veio de sapatos.

Gilberto morava em casarão no Bairro de Apipucos. Onde mais tarde a Fundação Joaquim Nabuco vai se instalar e se espraiar. Em torno do Açude de Apipucos, onde reinavam plácidas baronesas.

À beira do Açude, numa ponta, atrás da Igrejinha de Apipucos, reinavam três belas frondosas mangueiras. Dona Carminha, em sua casa, começou a inventar uns pratos. A cozinha e as panelas ao ar livre. Improvisada. Servia almoço a poucos, comida caseira, digamos, regional. À tarde, cachaça com caldinho de feijão, para muitos.

Um dos pratos, ali criado, era o hoje famoso concêntrico Arrumadinho.

"Dona Carminha, bote uma comida boa que a senhora vai ganhar dinheiro!", disse um freguês fiel. "Bora inventar", disse Dona Carminha para sua secretária. "A gente 
cozinha o feijão, a gente fez a charque cortadinha que nem a gente fazia, a gente fez a verdurinha que a gente fazia. E agora, para a gente colocar num prato, como é que vai ser? (...) Botemos o feijão, espalhemos, aí fizemos uma farofinha, botamos em cima. A verdurinha a gente colocava ao redor. Ficava o centro livre. Aí a gente pegava a charque, assava, e colocava lá."

O sucesso foi imediato. Em pouco tempo a cozinha caseira foi para o quintal. Vinte cinco mesas. Houve uma eleição entre os clientes para escolher o nome. Concorriam Açude e Mangueirão. Nasceu então o Mangueirão, ao ar livre, verde. Dona Carminha comprou sua casinha e um automóvel. Cultura e economia.

Nesta mesma época, em Olinda, outro prato popular começava sua carreira. O agora famoso Escondidinho. Desenhada não por horizontais círculos concêntricos, mas por verticais andares sobrepostos. No subsolo, purê de macaxeira. Macaxeira é nossa, a batata é inglesa. No solo, a camada de charque cortadinha ou desfiada. Finalmente, no primeiro andar queijo catupiry, tradicional marca brasileira. $\mathrm{O}$ forno a todos unia.

Paralelamente, nesta época, Edméa Falcão, Hélcio Santos e outros pesquisavam. Espiavam, diria Aloisio Magalhaes, o Nordeste, sua culinária e sua cachaça. A procura de nós mesmos. No Brasil profundo.

Encontraram o Escondidinho e o Arrumadinho em gestação. Aperfeiçoam. Criam então no Leblon, Rio de Janeiro, o pioneiro bar e restaurante Academia da Cachaça. No teto, a bandeira brasileira, como bandeirinhas de São João, reinventada pela designer Gisela Magalhães. O Escondidinho e o Arrumadinho fizeram aí seu pouso. Seu porto de exportação. Daí, ganharam o Brasil. Foram e estão muito além do regional. Ajudaram a fazer o Brasil.

Os quadros de Tarsila, de Di Cavalcanti, de Anita Malfatti, os textos de Mário de Andrade, de Oswald de Andrade, a música de Villa-Lobos são os bens que simbolizam a Semana de 22. O Mangueirão e a Academia da Cachaça desenharam, pintaram e cantaram outros bens imateriais: o Escondidinho e o Arrumadinho. Propagam as ideias do Manifesto Regionalista. A quem mais tarde vão se juntar à tapioca, ao acarajé, ao frevo e a tantos outros brasis.

\section{Considerações finais}

A ambição das cozinhas locais, sua organização e a exploração mercantil global, traduz-se hoje nas cotações da Bolsa de Nova York, ou de São Paulo, das ações dos conglomerados globais alimentícios como Nestlé, Ambev, Coca-Cola, Heinz, Burger King, Starbucks.

Não é só arroz doce.

Agora, se estas e outras ambições, antecipações, innuendos, insurgências do Manifesto foram tão imensas quanto o prazer que tinha para consigo mesmo ao descobri-las, é outra história. O que podemos apenas dizer é que foram, e continuam, extremamente ricas para nos ajudar a compreender melhor a nós mesmos. Ontem, hoje, talvez amanhã. 


\section{Referências}

FALCÃO, Joaquim. A luta pelo trono: Gilberto Freyre versus USP. In: FALCÃO, Joaquim; ARAÚJO, Rosa Maria Barbosa de. O Imperador das Ideias: Gilberto Freyre em questão, $2^{\text {a }}$ ed. Rio de Janeiro: Ed. Topbooks, 2010.

FAORO, Raymundo. Prefácio. In: FALCÃO, Joaquim. A Favor da Democracia. Pernambuco: Massangana/Bagaço, 2004.

MELLO, Evaldo Cabral de. O “ovo de Colombo" gilbertiano. In: FALCÃO, J.; ARAÚJO, Rosa Maria. O imperador das ideias. Rio de Janeiro: Topbooks, 2001.

TAVOLARO, Sergio B. F. Freyre e nossa 'modernidade tropical': Gilberto entre a originalidade e o desvio. Sociologias (UFRGS. Impresso), v. 15, p. 282-317, 2013. 
